Supporting Information for

\title{
Emissions measurements from household solid fuel use in Haryana, India: implications for climate and health
}

\section{co-benefits}

Robert M. Weltman ${ }^{a}$, Rufus D. Edwards ${ }^{\mathrm{a}^{*}}$, Lauren T. Fleming ${ }^{\mathrm{b}}$, Ankit Yadav ${ }^{\mathrm{c}}$, Cheryl L. Weyant ${ }^{\mathrm{d}}$, Brigitte Rooney ${ }^{\mathrm{e}}$, John H. Seinfeld ${ }^{\mathrm{f}}$, Narendra K. Arora ${ }^{\mathrm{c}}$, Tami C. Bond ${ }^{\mathrm{d}}$, Sergey A. Nizkorodovb, and Kirk R. Smith

${ }^{a}$ Department of Epidemiology, School of Medicine, University of California Irvine, CA 92697, USA

${ }^{b}$ Department of Chemistry, University of California Irvine, CA 92697, USA

' INCLEN Trust International, New Delhi, India

${ }^{\mathrm{d}}$ Department of Civil and Environmental Engineering, University of Illinois at Urbana-Champaign, Urbana, IL 61820, USA

e Division of Geological and Planetary Sciences, California Institute of Technology, Pasadena, CA 91125, USA

${ }^{\mathrm{f}}$ Division of Chemistry and Chemical Engineering, California Institute of Technology, Pasadena

${ }^{\mathrm{g}}$ School of Public Health, University of California, Berkeley, CA 94720, USA

*Corresponding author:

Rufus Edwards

Department of Epidemiology,

Room 1361 SE II 
University of California Irvine, CA 92697 USA

edwardsr@uci.edu

Contents of this file -8 pages consisting of 4 figures, 2 tables, 2 equations, and references.

Figure S1 on pages S3 and S4

Table S1 on page S4

Equation S1 on page S4

Equation S2 on page S4

Figure S2 on page S5

Table S2 on pages S6 and S7

Figure S3 on page S7

Figure $\mathrm{S} 4$ on page $\mathrm{S} 8$

References on page $\mathrm{S} 8$ 


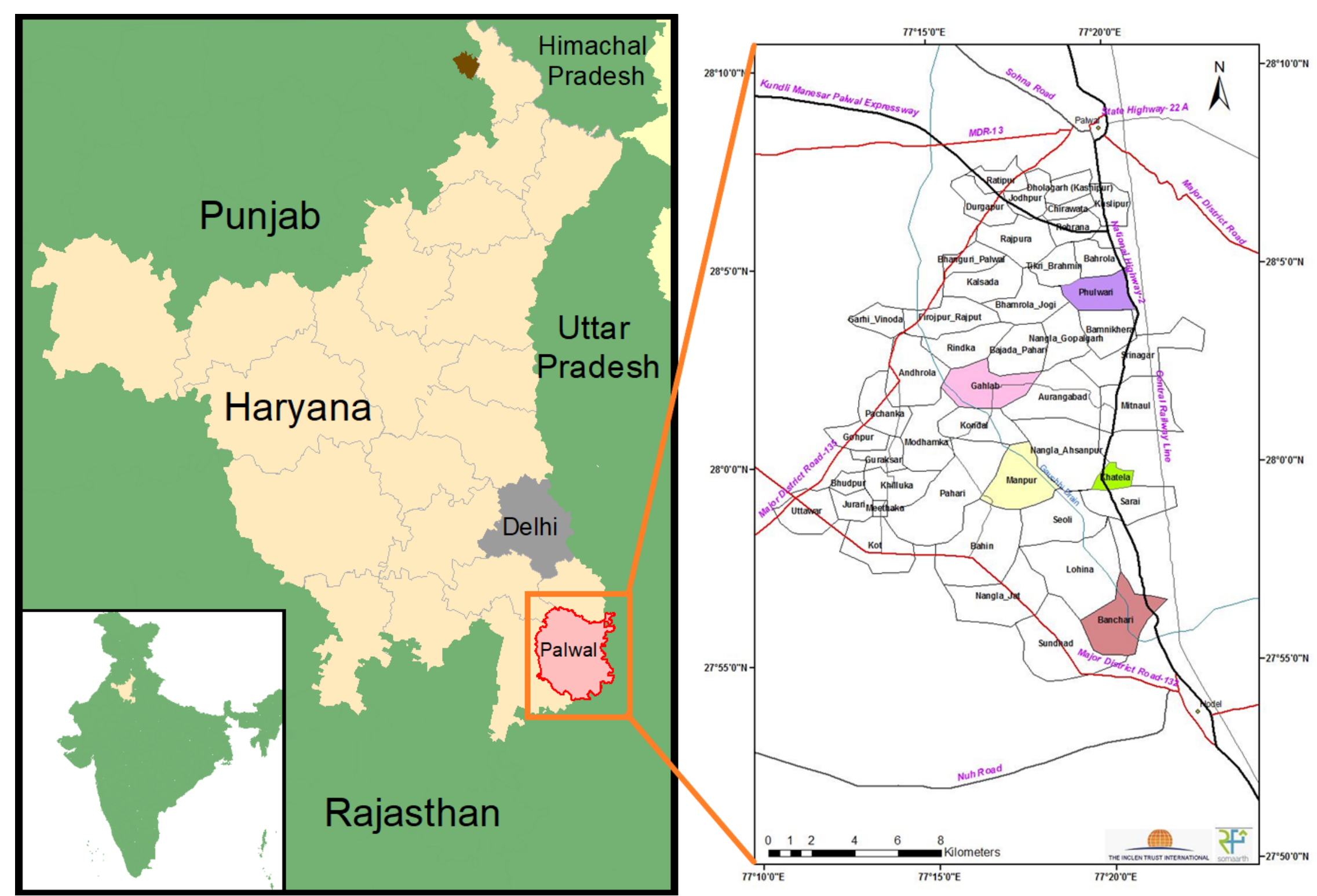


Figure S1: Map of the Palwal, Haryana, India study sites. The villages where measurements were conducted are in color in the right panel. Lines on maps represent approximate border lines for which there may not yet be full agreement and do not imply the expression of any opinion concerning the legal delimitation of frontiers or boundaries.

Table S1: Particulate and CO GWP 100 values used in this study are taken from Bond et al. $2013^{1}$. The GWP $\mathrm{G}_{20}$ value for CO used in this study is taken from Myhre et al. $2014^{2}$ using the value for South Asia for CO.

\begin{tabular}{ccc} 
Substance & $\mathrm{GWP}_{100}$ & $\mathrm{GWP}_{20}$ \\
\hline $\mathrm{CO}_{2}$ & 1 & 1 \\
$\mathrm{CO}$ & 2.8 & 5.7 \\
$\mathrm{EC}$ & 911 & 3204 \\
$\mathrm{OC}$ & -51 & -180
\end{tabular}

Equation S1. GWC $\mathrm{C}_{100} E F$ s are calculated by summing the $G W C_{100} E F s$ for each species $\left(C_{2}, C O, E C\right.$, and $\left.O C\right)$. The equation for summing the individual $G W C_{100} E F s$ is listed below:

$\mathrm{EFGWC}_{100}=\mathrm{EF}_{\mathrm{CO} 2} * f_{\mathrm{nr}}+\mathrm{EF}_{\mathrm{CO}} * f_{\mathrm{nr}} * 2.8+\mathrm{EF}_{\mathrm{CO}} *\left(1-f_{\mathrm{nr}}\right) *(2.8-1)+\mathrm{EF}_{\mathrm{EC}} * 911-\mathrm{EF}_{\mathrm{OC}} * 51$

Where $f_{n r}$ is the fraction of the fuel that is from non-renewable biomass.

Equation S2. $G W C_{20} E F s$ are calculated by summing the $G W C_{20} E F s$ for each species $\left(C O_{2}, C O, E C\right.$, and $\left.O C\right)$. The equation for summing the individual $G W C_{20} E F s$ is listed below:

$\mathrm{EFGWC}_{20}=\mathrm{EF}_{\mathrm{CO} 2} * f_{\mathrm{nr}}+\mathrm{EF}_{\mathrm{CO}} * f_{\mathrm{nr}} * 5.7+\mathrm{EF}_{\mathrm{CO}} *\left(1-f_{\mathrm{nr}}\right) *(5.7-1)+\mathrm{EF}_{\mathrm{EC}} * 3204-\mathrm{EF}_{\mathrm{OC}} * 180$

Where $f_{n r}$ is the fraction of the fuel that is from non-renewable biomass. 


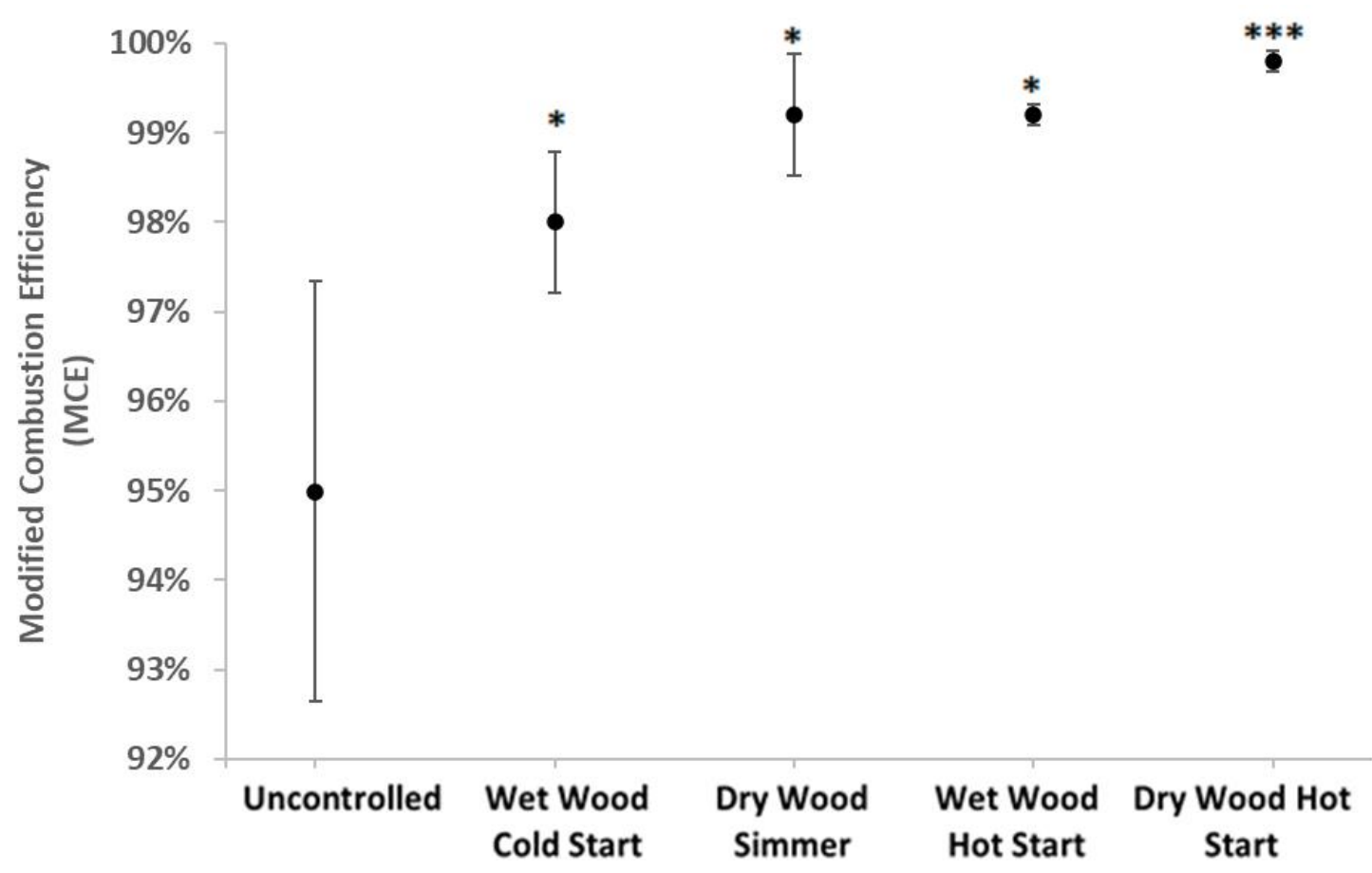

Figure S2: A comparison of the mean MCE for the Philips stove during uncontrolled testing in village homes and select laboratory ${ }^{3}$ results.

Standard error of the means as 95\% approximate confidence intervals are shown as error bars. Asterisks indicate significant differences with the uncontrolled testing according to Welch's two-sided tests (*: $p<0.05, * * *: p<0.01$ ). 
Table S2: Additional geometric mean EFs and ERs for the uncontrolled in-home and minimally directed tests of mixed-fuel use in the chulha cookstove alongside differences in the arithmetic mean values and two-sided t tests. Sample sizes were $n=7$ and 13 for the uncontrolled and controlled cooking tests respectively. Values for the uncontrolled and controlled tests are listed as geometric mean (arithmetic mean; arithmetic standard deviation). *: Sample size reduced by one due to a damaged filter.

\begin{tabular}{|c|c|c|c|c|}
\hline & Uncontrolled & Minimally Directed & Difference in Mean & $\begin{array}{l}\mathrm{P}(\mathrm{T}<=\mathrm{t}) \\
\text { Two-Tail }\end{array}$ \\
\hline $\begin{array}{c}\mathrm{CO}_{2} \mathrm{EF} \mathrm{g} / \mathrm{kg} \text { Dry } \\
\text { Fuel }\end{array}$ & $1092(1093 ; 36)$ & $967(968 ; 43)$ & 125 & $<0.01$ \\
\hline $\begin{array}{c}\mathrm{CO}_{2} \mathrm{EF} \mathrm{g} / \mathrm{kg} \\
\text { Carbon }\end{array}$ & $3213(3214 ; 88)$ & 3165 (3166;90) & 48 & 0.27 \\
\hline $\mathrm{CO}_{2} \mathrm{ER} \mathrm{g} / \mathrm{min}$ & $25.7(27.4 ; 10.3)$ & $25.0(25.1 ; 2.7)$ & 2.3 & 0.58 \\
\hline $\begin{array}{c}\text { CO EF g/kg Dry } \\
\text { Fuel }\end{array}$ & $84.0(84.3 ; 7.6)$ & $95.5(97.1 ; 18.4)$ & -12.8 & 0.04 \\
\hline $\begin{array}{l}\mathrm{CO} \mathrm{EF} \mathrm{g/kg} \\
\text { Carbon }\end{array}$ & $247.1(248.0 ; 22.8)$ & $312.5(317.1 ; 57.4)$ & -69.1 & $<0.01$ \\
\hline $\mathrm{COER} \mathrm{g} / \mathrm{min}$ & $2.0(2.1 ; 0.9)$ & $2.5(2.5 ; 0.5)$ & -0.4 & 0.33 \\
\hline $\begin{array}{c}\mathrm{PM}_{2.5} \mathrm{EF} \mathrm{g} / \mathrm{kg} \\
\text { Carbon }\end{array}$ & $25.7(32.3 ; 22.3)$ & $40.4(41.4 ; 7.8)^{*}$ & -8.7 & 0.35 \\
\hline
\end{tabular}




\begin{tabular}{|c|c|c|c|c|}
\hline $\begin{array}{l}\mathrm{PM}_{2.5} \mathrm{ER} \\
\mathrm{mg} / \mathrm{min}\end{array}$ & $206(311 ; 271)$ & $320(327 ; 69)^{*}$ & -16 & 0.88 \\
\hline $\begin{array}{c}\text { EC EF g/kg } \\
\text { Carbon }\end{array}$ & $1.3(1.7 ; 1.5)^{*}$ & $2.1(2.2 ; 0.8)^{*}$ & -0.5 & 0.47 \\
\hline EC ER $\mathrm{mg} / \mathrm{min}$ & $10(17.6 ; 23)^{*}$ & $17(17.8 ; 7)^{*}$ & -0.2 & 0.98 \\
\hline $\begin{array}{c}\mathrm{OC} \text { EF g/kg } \\
\text { Carbon }\end{array}$ & $11.6(17.6 ; 16.8)^{*}$ & $18.5(18.7 ; 3.1)^{*}$ & -1.1 & 0.88 \\
\hline OC ER $\mathrm{mg} / \mathrm{min}$ & $88(175 ; 186)^{*}$ & $147(149 ; 27)^{*}$ & 26 & 0.74 \\
\hline
\end{tabular}

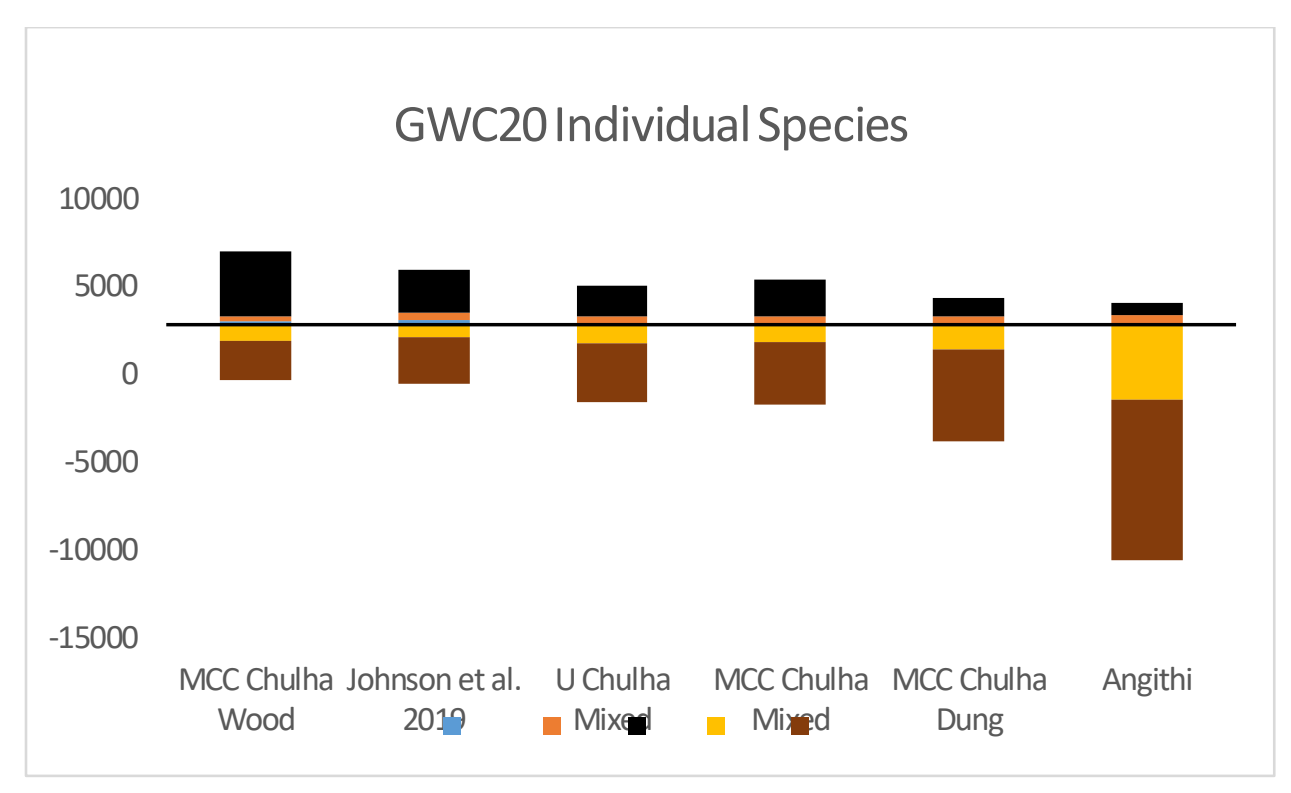

Figure S3: A stacked bar chart of the contribution of each species to total $G W C_{20}$. 


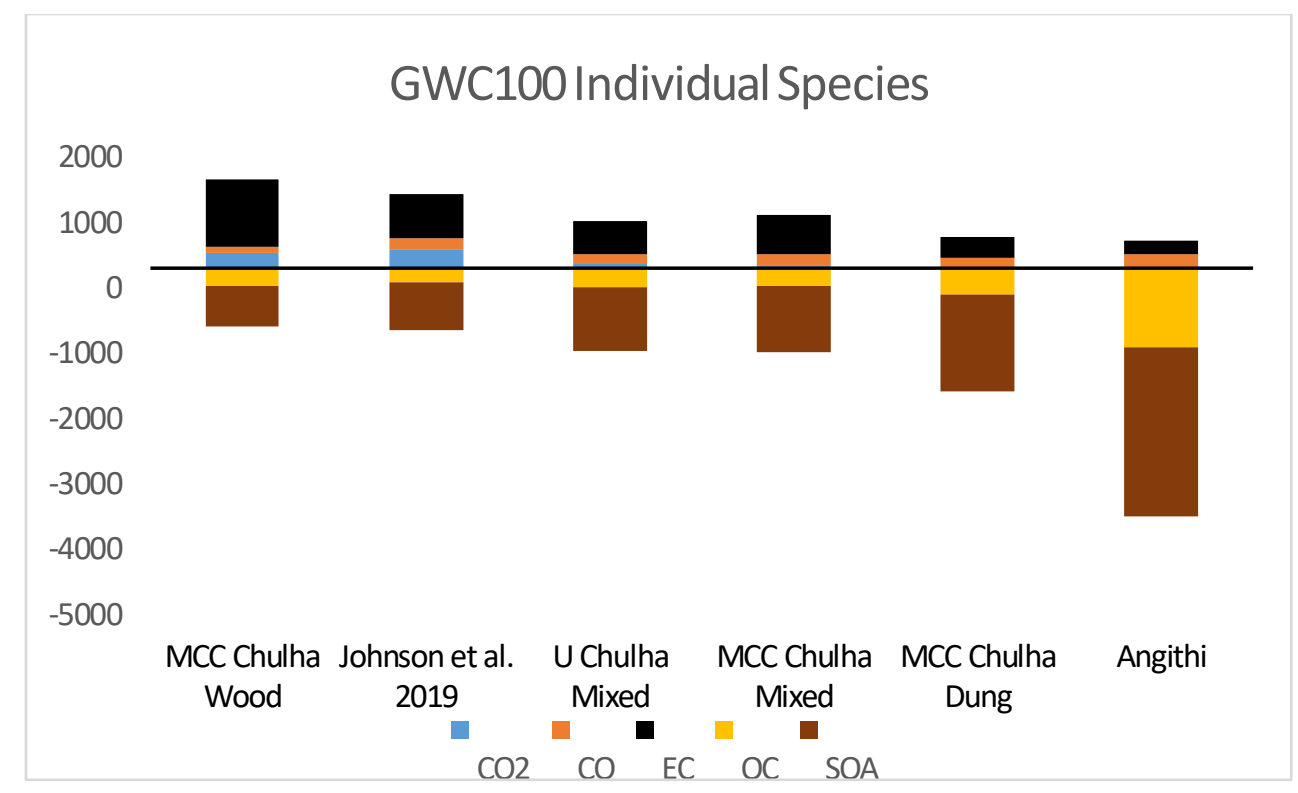

Figure S4: A stacked bar chart of the contribution of each species to total $G W C_{100 .}$

\section{References}

1. Bond, T. C.; Doherty, S. J.; Fahey, D. W.; Forster, P. M.; Berntsen, T.; DeAngelo, B. J.; Flanner, M. G.; Ghan, S.; Kärcher, B.; Koch, D., Bounding the role of black carbon in the climate system: A scientific assessment. Journal of Geophysical Research: Atmospheres 2013, 118, (11), 5380-5552.

2. Myhre, G.; Shindell, D.; Pongratz, J., Anthropogenic and natural radiative forcing. Contribution to the Fifth Assessment Report of the Intergovernmental Panel on Climate Change 2014.

3. Jetter, J.; Zhao, Y.; Smith, K. R.; Khan, B.; Yelverton, T.; DeCarlo, P.; Hays, M. D., Pollutant emissions and energy efficiency under controlled conditions for household biomass cookstoves and implications for metrics useful in setting international test standards.

Environmental science \& technology 2012, 46, (19), 10827-10834. 